\title{
Dielectric function and its predicted effect on localized plasmon resonances of equiatomic $\mathrm{Au}-\mathrm{Cu}$
}

\author{
K.S.B. De Silva, ${ }^{1}$ A. Gentle, ${ }^{1}$ M. Arnold, ${ }^{1}$ V.J. Keast, ${ }^{2}$ M B Cortie ${ }^{1}$ \\ ${ }^{1}$ Institute for Nanoscale Technology, University of Technology Sydney, PO Box 123, Broadway, \\ NSW 2007, Australia \\ ${ }^{2}$ School of Mathematical and Physical Sciences, University of Newcastle, Callaghan NSW 2308, \\ Australia
}

\begin{abstract}
Equiatomic $(\mathrm{Au}, \mathrm{Cu})$ solid solution orders below $658 \mathrm{~K}$ to form tetragonal $\mathrm{AuCu}(\mathrm{I})$ phase with significant changes in physical properties and crystal structure. The effect of ordering on the dielectric function of the material is controversial however, with inconsistent results reported in the literature. Since the nature of any localized surface plasmon resonance (LSPR) in nanostructures is very sensitive to dielectric function, this uncertainty hinders the use of $\mathrm{AuCu}$ in plasmonic devices or structures. Therefore, we re-examine the question using a combination of measurements and computations. We find that no significant change in the dielectric function occurs when this material becomes ordered, at least over the range of photon energies relevant to LSPRs. The likely properties of LSPRs in plasmonic devices made of $\mathrm{AuCu}$ are analyzed. Use of the alloy offers some advantages over pure $\mathrm{Cu}$, however pure $\mathrm{Au}$ would still be the superior option in most situations.
\end{abstract}

PACS numbers: 78.66. Bz, 78.20.Ci, 73.20.Mf, 81.15.Ef, 68.37.Lp, 68.37.Hk, 71.15.Mb 


\section{Introduction}

$\mathrm{Au}$ and $\mathrm{Cu}$ form a continuous, face-centered cubic (fcc) solid solution, designated $(\mathrm{Au}, \mathrm{Cu})$, between $683 \mathrm{~K}$ and the melting point of $\sim 1180 \mathrm{~K}$. However, depending on stoichiometry, this solid solution will transform at lower temperatures to one of the ordered superlattices $\mathrm{Au}_{3} \mathrm{Cu}, \mathrm{AuCu}(\mathrm{I}), \mathrm{AuCu}$ (II) or $\mathrm{AuCu}_{3}$ [3] (the Roman numerals I and II are used to differentiate two different crystal structures). These intermetallic compounds have different crystal structures and physical properties to those of the parent fcc $(\mathrm{Au}, \mathrm{Cu})$. For example, their electrical resistivity is significantly reduced but their hardness, especially that of $\mathrm{AuCu}(\mathrm{I})$, is increased [4-6]. The transformation of equiatomic $(\mathrm{Au}, \mathrm{Cu})$ to tetragonal $\mathrm{AuCu}(\mathrm{I})$ has been extensively studied in the past [8] and proceeds in a first-order fashion via an orthorhombic intermediary known as $\mathrm{AuCu}(\mathrm{II})$. However, direct transformation of $(\mathrm{Au}, \mathrm{Cu})$ to $\mathrm{AuCu}(\mathrm{I})$ at lower temperatures can also occur [10].

The dielectric functions, $\varepsilon(\omega)=\varepsilon_{1}(\omega)+i . \varepsilon_{2}(\omega)$, of $(\mathrm{Au}, X)$ solid solutions have sometimes been reported to be an approximately linear interpolation of those of the elemental endpoints [11-13] and, indeed, the plasmon resonance characteristics of $(\mathrm{Au}, \mathrm{Cu})$ alloy nanoparticles of various compositions may be varied smoothly between those of the elements [14-17]. However, the dependency of dielectric function on composition will be non-linear in the general case. For example, calculations predict that 12.5 at.\% substitutional additions of $\mathrm{Al}, \mathrm{Mg}, \mathrm{Cd}$ or $\mathrm{Zn}$ to $\mathrm{Au}$ may result in a slight strengthening of the localized surface plasmon resonance (LSPR), but further additions that are large enough to form intermetallic compounds will reverse this advantage and significantly attenuate the LSPR [18]. In addition, it is also widely accepted that crystal structure should, in general, have an effect on $\varepsilon(\omega)$, so that, for example, the dielectric 
function of the $\mathrm{Au}_{\mathrm{x}} \mathrm{Cu}$ intermetallic compounds should be different to those of a disordered parent solid solution of the same composition [11, 19-21]. For example, ordering of $(\mathrm{Au}, \mathrm{Cu})$ in the range of 20 to 50 at.\% $\mathrm{Cu}$ has been reported to cause an increase in the energy of the absorption threshold, going, for example, from $2.26 \mathrm{eV}$ to $2.31 \mathrm{eV}$ at 35 at.\% $\mathrm{Cu}[11]$. From inspection of the binary phase diagram for $\mathrm{Au}-\mathrm{Cu}$ it appears that such a change is associated with the formation of $\mathrm{Au}_{3} \mathrm{Cu}$ or $\mathrm{AuCu}(\mathrm{I})$. The associated shift in the absorption threshold would strengthen any LSPR located in this range.

The situation for equiatomic $\mathrm{AuCu}$ has been investigated by Scott and Muldawer [19], Koster and Stahl [7] (as cited in Henkel et al.[1]) and Rivory [9]. In this case, the ordering transition causes a significant change in the crystal structure of the material from cubic (Fm-3m structure with $a=0.389 \mathrm{~nm})$ to tetragonal (P4/mmm with $a=0.289$ $\mathrm{nm}, c=0.367 \mathrm{~nm}$ if indexed on a two-atom bct unit cell, or $a=0.397, c=0.367$ if indexed on a four-atom fct unit cell derived directly from the parent fcc). The effect of this phase transformation on the dielectric function is unclear, however, especially at the lower energies $(<1.8 \mathrm{eV}$, or $\lambda>700 \mathrm{~nm})$. Scott and Muldawer reported that ordering decreased $\varepsilon_{2}$ from 1.5 to 1.1 at $1.8 \mathrm{eV}(700 \mathrm{~nm})$, with a further decrease to less than 0.5 units between about 1 and $1.5 \mathrm{eV}(1240$ to $830 \mathrm{~nm})$. On the face of these values, this would be the optimum range in which to design for a strong LSPR in a suitably shaped $\mathrm{AuCu}(\mathrm{I})$ nanostructure since a low value of $\varepsilon_{2}$ is considered beneficial in this context. In contrast, Koster and Stahl reported an increase of $\varepsilon_{2}$ to 3.4 to 4.4 at $\sim 1.8 \mathrm{eV}$. Rivory found little change in $\varepsilon_{2}$ on ordering, except for a small increase centered on about 3.5 $\mathrm{eV}$, which is well above the absorption threshold and therefore not a suitable energy to excite a LSPR anyway. 
One implication of a decreased $\varepsilon_{2}$ on ordering in the lower energy part of the visible spectrum is that the longitudinal plasmon resonance of $\mathrm{AuCu}(\mathrm{I})$ nanorods should be sharper and stronger than that of $(\mathrm{Au}, \mathrm{Cu})$ nanorods of the same shape and composition [1] since, as we will discuss later, the magnitude of $\varepsilon_{2}$ is one of the factors controlling the quality of a localized plasmon resonance in a nanostructure. Similar considerations would apply to $\mathrm{Au}_{50} \mathrm{Cu}_{50}$ nanoshells and nanotriangles as these would also have LSPRs in this part of the spectrum.

Since there has been some recent interest in the synthesis of hybrid $\mathrm{Au} / \mathrm{Cu}$ nanoparticles and their optical properties [1, 17], it would be helpful to resolve the discrepancies in the literature. Here we address the specific case of $\mathrm{AuCu}(\mathrm{I})$ and its parent solid solution $(\mathrm{Au}, \mathrm{Cu})$. We carried out experimental measurements and performed density functional theory (DFT) calculations to determine whether ordering of $\mathrm{Au}_{50} \mathrm{Cu}_{50}$ from $(\mathrm{Au}, \mathrm{Cu})$ to $\left.\mathrm{AuCu}(\mathrm{I})\right)$ changes the optical properties and, hence, the strength of any potential LSPRs.

\section{Experimental Procedure}

\subsection{Fabrication and characterization of samples}

Bulk alloy samples were made by melting the pure elements in an $\mathrm{Al}_{2} \mathrm{O}_{3}$ crucible, located within a low-oxygen environment formed by carbon and aluminum heat-treating foil. Samples were heat-treated in a muffle furnace. The disordered sample was produced by heat-treating at $500{ }^{\circ} \mathrm{C}$ for $1 \mathrm{~h}$ and quenching into iced brine while the ordered sample was produced by heat-treating at $375^{\circ} \mathrm{C}$ for $1 \mathrm{~h}$ followed by furnace cooling. 
Thin film samples were made by co-deposition of the elements onto a glass slide using magnetron sputtering. Samples were heat-treated within a chamber which had a heated substrate and a flow-through of low pressure $\mathrm{H}_{2}$. The 'quenched' sample was produced by annealing for 20 minutes at $450{ }^{\circ} \mathrm{C}$, followed by a rapid cool that was engineered by switching off the heater and increasing gas flow. The sample took $\sim 60$ seconds to cool from $450^{\circ} \mathrm{C}$ to $250^{\circ} \mathrm{C}$ under these conditions. Formation of the ordered phase was achieved by annealing first for 20 minutes at $450{ }^{\circ} \mathrm{C}$ then allowing the temperature to fall to $375^{\circ} \mathrm{C}$, dwelling there for 20 minutes, and finally cooling to room temperature.

X-ray diffraction (XRD) was carried out on samples of the alloy using a Siemens D5000 X-ray diffractometer and CuK $\alpha$ radiation $(1.5406 \AA)$ (the bulk samples were polished prior to conducting XRD). The lattice parameters of the bulk material were estimated from the position of the $\{111\}$ and $\{002\}$ peaks, and that of the thin films from the $\{022\}$ peaks, in both cases as indexed on the face-centred tetragonal unit cell. Energy dispersive spectra of samples of the alloy were obtained using a Zeiss Evo LS15 SEM with a Bruker EDS Quantax 400. Samples for transmission electron microscopy (TEM) were prepared from the bulk alloys by mechanical polishing, dimple grinding and ion milling. Electron diffraction and bright field imaging were performed in a JEOL $2100 \mathrm{LaB}_{6}$ TEM and lattice imaging in a JEOL2100F TEM .

Optical characterization was carried out using a V-VASE Ellipsometer by J.A. Woollam Co. and a Perkin Elmer Lambda 950 UV-Vis-IR spectrometer with universal reflectance accessory. The resultant data was analyzed using WVASE ellipsometric software. In the case of the thin films back-side reflectance measurements were carried out (taking into account the optical properties of the glass substrate) in order to extract 
the dielectric constants. This circumvented the influence of surface effects such as roughening, thermal etching or oxidation which may have occurred during annealing,

\subsection{Calculations}

DFT calculations of the density of states (DOS) and dielectric functions were carried out using the WIEN2K code [22]. The generalized gradient approximation (GGA) of Perdew, Burke, and Ernzerhof (PBE) was used for the exchange-correlation potential [23] and the number of $k$-points was tested for convergence. The optical properties were obtained according to the method of Ambrosch-Draxl and Sofo [24] using the OPTIC module. This approach relies on the random phase approximation (RPA) and neglects local field effects. $\mathrm{AuCu}(\mathrm{I})$ was simulated using a body centered tetragonal (bct) unit cell with $a=2.804, c=3.673 \AA$ with $\mathrm{Au}$ at $(0,0,0)$ and $\mathrm{Cu}$ at $(0.5,0.5,0.5)$. As random disordered structures cannot be simulated within WIEN2K, the effect of disorder in $(\mathrm{Au}, \mathrm{Cu})$ phase was explored by using three different periodic structures with various atomic arrangements. Unit cell D1 was the bet unit cell that can be derived from the fcc one by the Bain correspondence and had $a=2.751, c=3.89 \AA$ with $\mathrm{Au}$ at $(0,0,0)$ and $\mathrm{Cu}$ at $(0.5,0.5,0.5)$. This is the same atomic arrangement as the ordered $\mathrm{AuCu}(\mathrm{I})$ but with cubic packing and a lattice parameter equivalent to that found in the disordered alloy. Unit cell D2 was a 1x2 supercell of the fcc structure ( $a=3.89 \AA)$, with atoms of $\mathrm{Cu}$ located as shown in figure 1(a). Finally, cell D3 was a 4x1 supercell of fcc ( $a=3.89 \AA)$ with $\mathrm{Cu}$ atoms located as shown in figure 1(b). For comparison, the dielectric functions of pure $\mathrm{Au}$ and $\mathrm{Cu}$ were also calculated. 


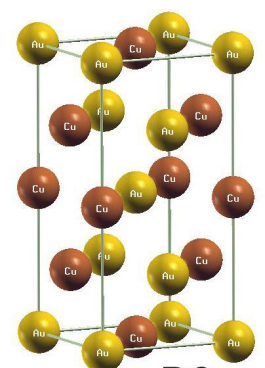

D2

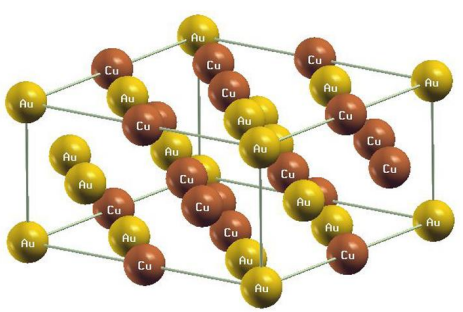

D3

Figure 1. (Color online) Atomic configuration of two $\mathrm{Au}-\mathrm{Cu}$ unit cells based on equiatomic fcc (Au, Cu), (a) unit cell D2, (b) unit cell D3.

The effect of the different measured or calculated dielectric functions on the quality of any localized surface plasmon resonances in hypothetical nanostructures was simulated using analytical expressions derived from Mie theory. It is assumed as a first approximation that the dielectric function of the nanoparticles would be the same as that of the bulk material and that their surfaces would be smooth and un-oxidized. In practice. In practice, oxidation of the $\mathrm{Cu}$ component is likely [25] and the resonances of real particles would be slightly red-shifted relative to those calculated using this idealized scenario.. The methodology is explained further in Arnold and Blaber [26].

\section{Results}

\subsection{Microstructure of samples}

The atomic composition of the bulk samples was found by EDS to be 50.5 at.\% $\mathrm{Au}-49.5$ at. $\% \mathrm{Cu}$, whereas in the films the atomic composition was 49.6 at.\% Au- 50.4 at.\% $\mathrm{Cu}$. From XRD it was determined that the furnace-cooled bulk sample had a $c / a$ ratio of 0.934 , indicating that it was fully ordered to $\mathrm{AuCu}(\mathrm{I})$ phase. The bulk sample that had been quenched from $500{ }^{\circ} \mathrm{C}$ had a $c / a$ ratio of $\sim 0.98$ (if indexed on the fct unit 
cell), indicating that it had ordered slightly during the quench. This is typical behavior for $\mathrm{AuCu}$ since some ordering will inevitably occur in it even during a water quench $[27,28]$. The microstructure of the fully-ordered sample contained the laths that are characteristic [28] of ordered domains within $\mathrm{AuCu}(\mathrm{I})$, figure 2(a), whereas that of the quenched sample was relatively featureless, as expected, figure 2(b). The satellite reflections on the electron diffraction patterns of the furnace-cooled sample indicated ordering to a superstructure but these reflections are absent in the quenched sample supporting the other evidence that no long range order had been established in that case. The "ripple" structure observed in the quenched sample is most likely due to ion milling damage, as supported by the observation of reduced contrast in the lattice images due to amorphized surface layers. 

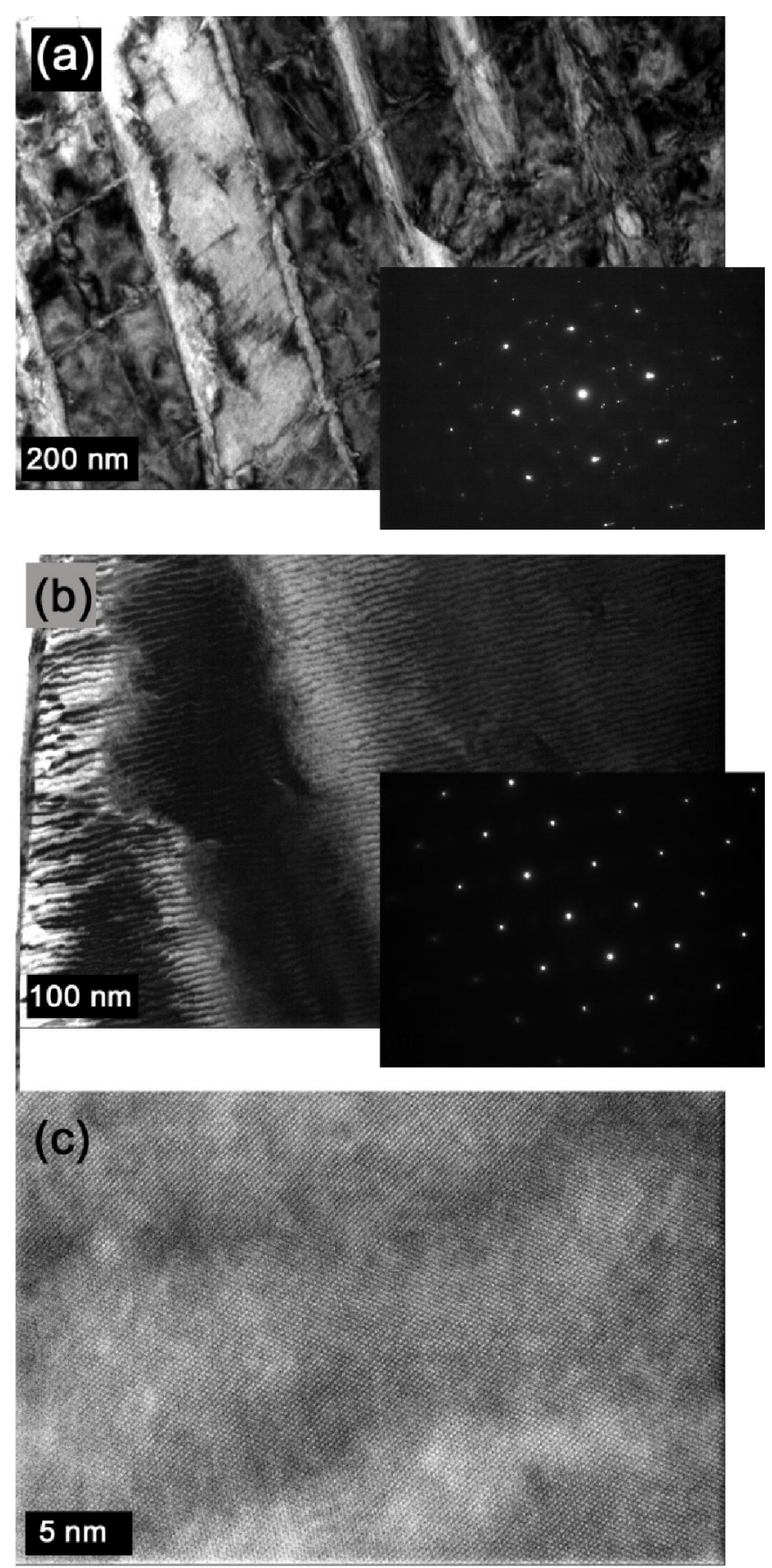

Figure 2. Microstructure of $\mathrm{Au}-\mathrm{Cu}$ samples. (a) Transmission electron micrograph and electron diffraction pattern of furnace-cooled sample. (b) Transmission electron micrograph and electron diffraction pattern of quenchedcooled sample. (c) Atomic resolution transmission electron micrograph of quenched sample along [011] direction showing absence of laths or twins. 
Due to a strong crystallographic texture in the thin films, only a few peaks were detected by XRD. However, the presence of a peak at $d=0.1360 \mathrm{~nm}$, figure 3 , is characteristic of $\{220\}_{(\mathrm{Au}, \mathrm{Cu})}$ (implying a fcc lattice parameter of $0.384 \mathrm{~nm}$, and, from the literature [8], a $\mathrm{Cu}$ content of the order of 55 to 57 at.\%), while peaks at $d=0.1424$ $\mathrm{nm}$ and $d=0.1473 \mathrm{~nm}$ matched $(220)_{\mathrm{AuCu}(\mathrm{I})}$ and $(022)_{\mathrm{AuCu}(\mathrm{I})}$ (if indexed on a fct cell) implying $a \approx 0.396 \mathrm{~nm}, c \approx 0.371 \mathrm{~nm}$, and $c / a=0.937$, i.e. practically fully ordered $\mathrm{AuCu}(\mathrm{I})$. Using these observations we concluded that (i) the material was fcc but only weakly crystalline in the as-deposited state, (ii) after heat treatment at $450{ }^{\circ} \mathrm{C}$ followed by a rapid cool, the fcc grains in the film had annealed and grown considerably, as indicated by a significant increase in the intensity of the $\{220\}$ peak, and (iii) re-heattreating the crystalline structure for 20 minutes at $375^{\circ} \mathrm{C}$ converted the fcc structure to $\operatorname{AuCu}(\mathrm{I})$, as evidenced by the splitting of the $\{220\}_{\text {fcc }}$ peak into $(220)_{\text {fct }}$ and $(022)_{\text {fct. }}$.

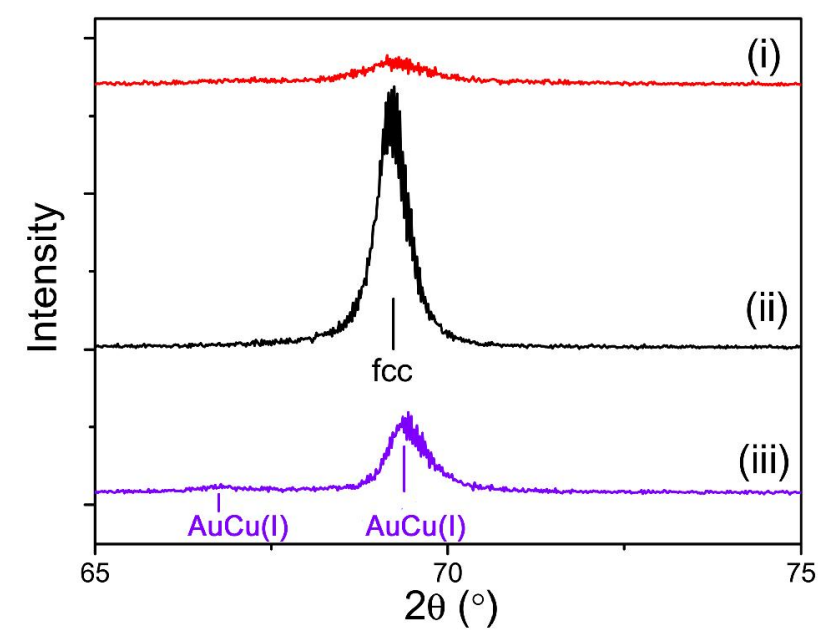

Figure 3. (Color online) Portion of the X-ray diffraction pattern of a series of thin film samples. (i) Poorly crystalline fcc sample after deposition at room temperature. (ii) Heat treating at $450{ }^{\circ} \mathrm{C}$ causes grains to grow and intensity of the $\{220\}_{\text {fcc }}$ peak to grow. (iii) A further heat treatment for 20 minutes at $375^{\circ} \mathrm{C}$ causes the sample to transform to $\mathrm{AuCu}(\mathrm{I})$, as indicated by the appearance of reflections characteristic of the $(220)_{\mathrm{AuCu}(\mathrm{I})}$ and $(022)_{\mathrm{AuCu}(\mathrm{I})}$. 
(a)

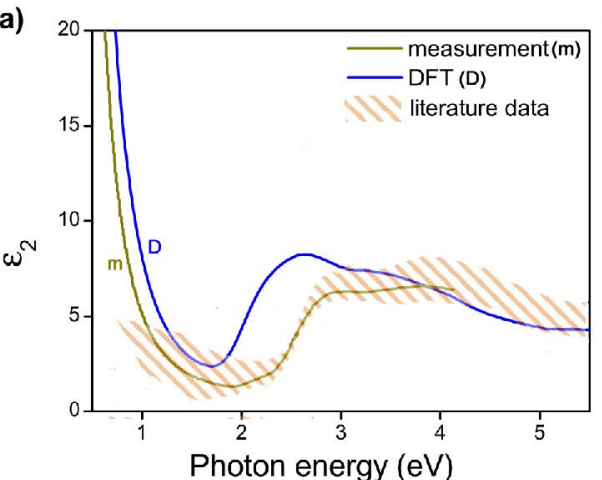

(c)

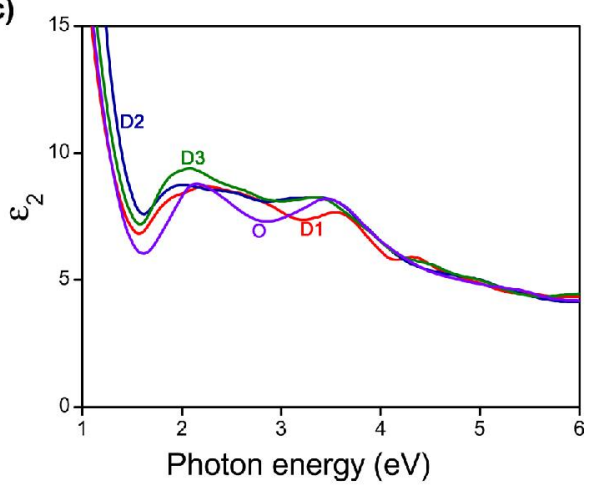

(b)

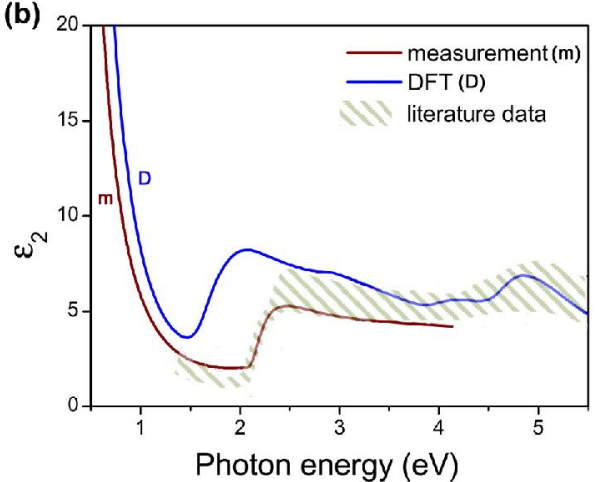

(d)

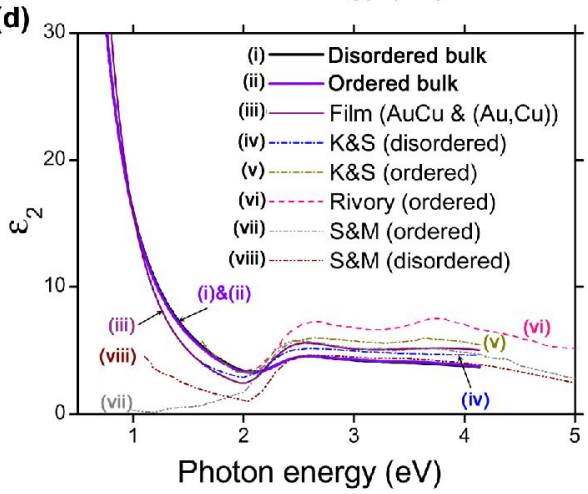

Figure 4. (Color online) $\varepsilon_{2}$ values of $\mathrm{Au}, \mathrm{Cu}, \mathrm{AuCu}$ and ( $\mathrm{Au}, \mathrm{Cu}$ ). (a) Calculated and measured values for $\mathrm{Au}$. (b) Calculated and measured values for $\mathrm{Cu}$. Literature values for elemental $\mathrm{Au}$ and $\mathrm{Cu}$ are from Henkel et al. [1] and the CRC Handbook of Chemistry and Physics [2]. (c) $\varepsilon_{2}$ for the ordered (O) and disordered (D1-D3) $\mathrm{AuCu}$ unit cells calculated here using DFT. (d) Experimental values of $\varepsilon_{2}$. Values of $\varepsilon_{2}$ for $\mathrm{AuCu}$ from the literature are shown from Köster and Stahl ('K\&S') [7], Rivory [9] and Scott and Muldawer ('S\&M')

Measured and calculated values of $\varepsilon_{2}$ for the pure elements are shown in panels (a) and (b) of figure 4 and serve as a calibration of our methodology. Our measured values lie within the scatter bands of values reported in the literature for each element. The calculated $\varepsilon_{2}$ for $\mathrm{Cu}$ correctly depicts the well-known double peak [11] of the interband transitions from the $d$-band. However the position of the absorption edge for both elements is too low by about $0.5 \mathrm{eV}$. This is a known limitation of the RPA for the noble metals [29-32]. Absolute magnitudes of the computed $\varepsilon_{2}$ for $\mathrm{Au}$ and $\mathrm{Cu}$ lie within 
the envelope of experimental errors known to be introduced by factors such as surface roughness, void fraction or stress [33].

The calculated effect of ordering on the optical properties of the Au-Cu alloy is shown in figure 4(c). It is clear that the optical properties of the four simulated structures are predicted to be very similar. Although a true disordered structure has not been calculated, the results from these different periodic structures indicate that the effect of the site occupancy is relatively minor. Measured values for the $\varepsilon_{2}$ of these materials are shown in figure 4(d) alongside data taken from the literature $[1,9,19]$. The present results indicate that neither the ordering nor the onset of tetragonality accompanying it make much difference to the optical properties. For $\varepsilon_{2}$, the measured values match the data of Koster and Stahl between 1.5 and $2.0 \mathrm{eV}$, and those of Rivory between 2.0 and $2.3 \mathrm{eV}$. The values of $\varepsilon_{2}$ found for our thin films are essentially identical to those reported by Koster. In contrast, however, above the absorption threshold, the $\varepsilon_{2}$ values of our bulk samples are lower than the literature values by about 3 units- a significant difference.

The absorption edge itself, whether of $(\mathrm{Au}, \mathrm{Cu})$ or $\mathrm{AuCu}(\mathrm{I})$, is positioned about mid-way between that of the elements as expected from a simple rule of mixing. Below the absorption edge (ie. photon energies below about $2.1 \mathrm{eV}$ ) the $\varepsilon_{2}$ data of Scott and Muldawer have values comparable to pure $\mathrm{Cu}$ or $\mathrm{Au}$ whereas our measurements, and the data of Koster, indicate a considerably larger $\varepsilon_{2}$.

The values of $\varepsilon_{1}$ are shown in figure 5. The values for pure $\mathrm{Au}$ and $\mathrm{Cu}$ lie within the range of the values reported in the literature. It is clear that the measured $\varepsilon_{1}$ of the bulk material lies between the published values of $\varepsilon_{1}$ for $\mathrm{Au}$ and $\mathrm{Cu}$ for energies greater 
than about $2.1 \mathrm{eV}$. Below that energy the $\varepsilon_{1}$ is slighter greater than expected. However, the values for the thin film $\mathrm{Au}, \mathrm{Cu}$ samples are indistinguishable from those of $\mathrm{Cu}$. The values found for $\varepsilon_{1}$ are very similar to those reported by Koster and Stahl [7] (as cited by Henkel [1]).

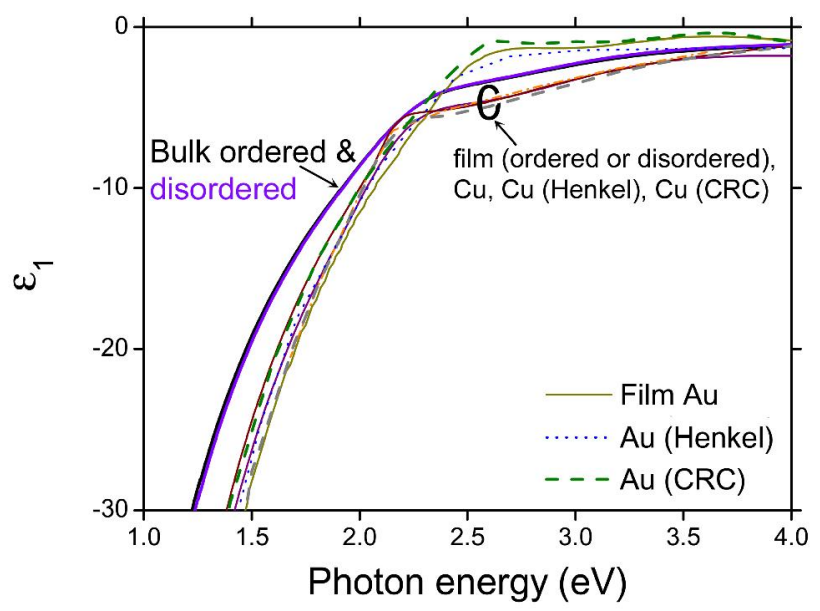

Figure 5. (Color online) Measured, calculated and literature values for $\varepsilon_{1}$ for $(\mathrm{Au}, \mathrm{Cu})$ and $\mathrm{AuCu}(\mathrm{I})$. Literature values for elemental $\mathrm{Au}$ and $\mathrm{Cu}$ are from Henkel et al. [1] and the CRC Handbook of Chemistry and Physics [2]

\section{Discussion}

The difference in dielectric function between the bulk and thin film samples may be attributed to the large grain size in the bulk samples, which are also relatively free of defects. The increased grain boundary scattering and porosity of the sputtered samples relative to the bulk ones should lead to them having a considerably greater value of $\varepsilon_{2}$, in agreement with the observations here.

The calculated data for $\varepsilon_{2}$ and that measured by Rivory and Koster show a double peak (at $\sim 2.1 \mathrm{eV}$ and $\sim 3.5 \mathrm{eV}$ ) above the absorption edge. Rivory correlated the appearance of the higher energy peak to the onset of ordering, and attributed it to 
transitions from the lower d-bands to the Fermi level. Although the present DFT calculations produce this peak irrespective of ordering, disordering does cause a flattening out of the double peak observed in the ordered structure. This is also supported by the DOS which shows a more attenuated double-peaked structure in the d-band, figure 6. Broadly speaking, the DOS also has two high regions, with the one closest to the Fermi level being mostly due to $\mathrm{Cu}$ while the deeper lying region of high DOS is due to Au. The features of the DOS are correlated with the two peaks in $\varepsilon_{2}$.

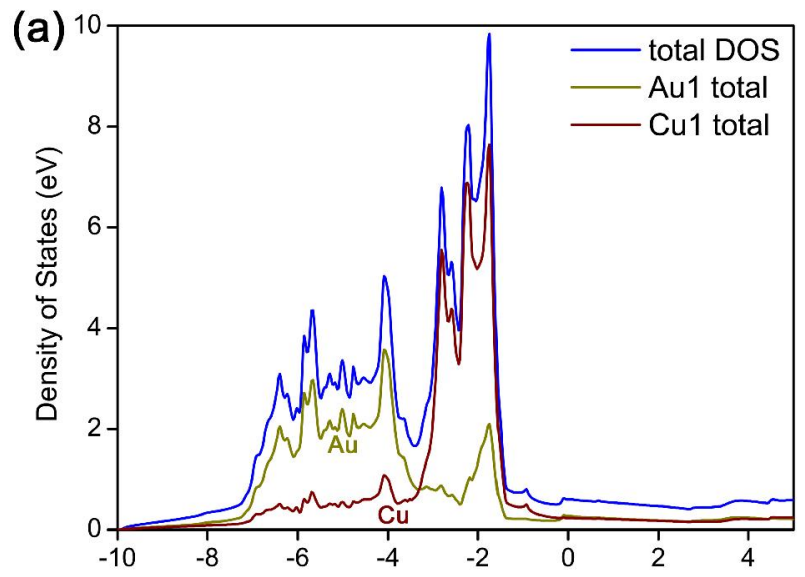

(b) Energy (eV)

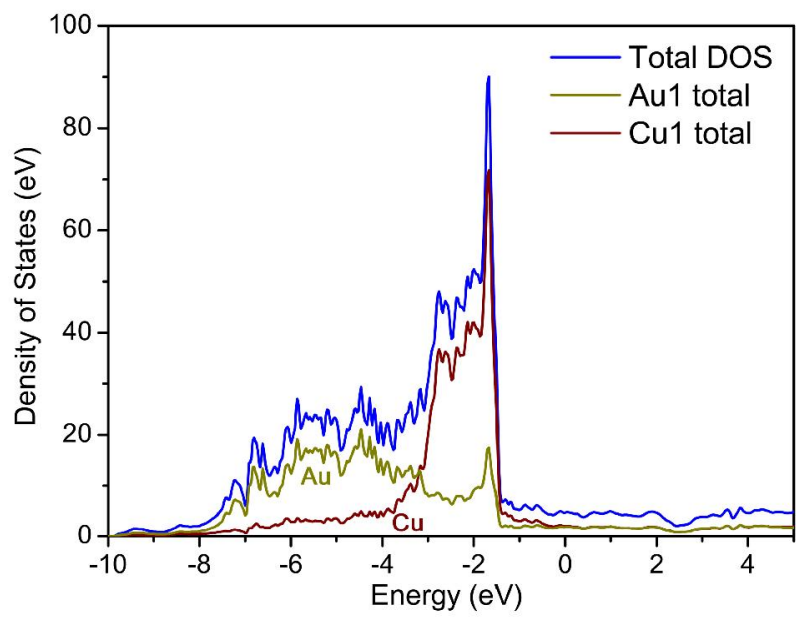

Figure 6. (Color online) Density of states for (a) ordered alloy and (b) the disordered alloy (corresponding to the $4 \times 1$ supercell D3). 
(a)

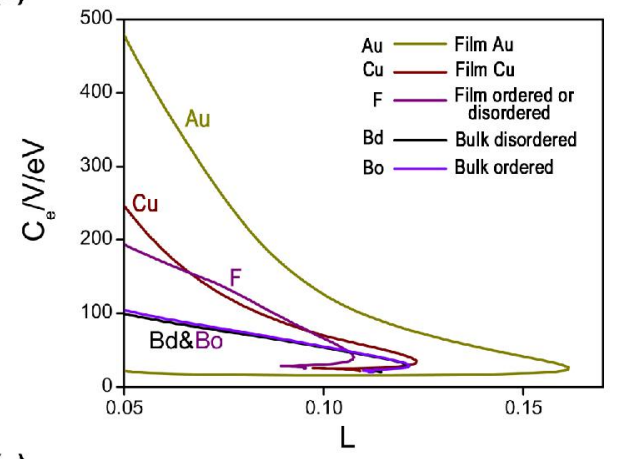

(c)

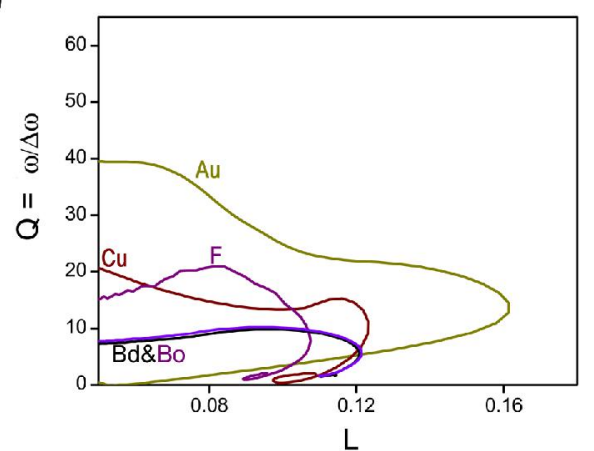

(b)

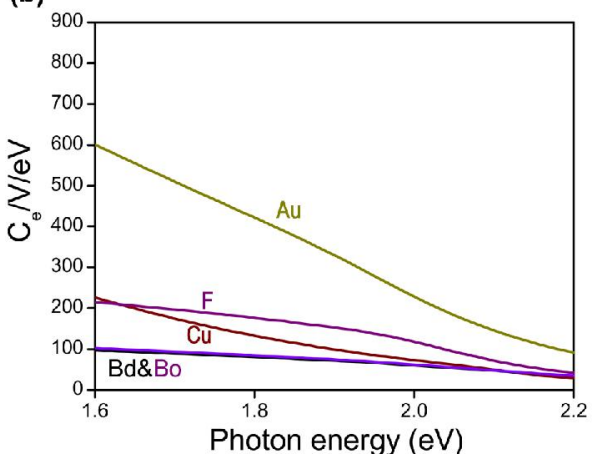

(d)

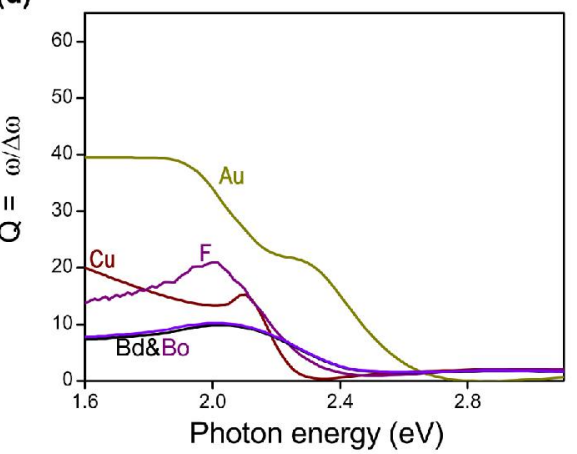

Figure 7. (Color online) Comparison of the predicted capability of $\mathrm{Au}, \mathrm{Cu}$ and various equiatomic $\mathrm{Au}-\mathrm{Cu}$ materials to generate localized surface plasmon resonances in suitable nanostructures.

Although $\varepsilon_{1}$ and $\varepsilon_{2}$ are not independent variables (being connected to each other through the Kramers-Kronig relationship) their effect on LSPRs can be conceptually separated so that $\varepsilon_{1}$ can be considered to control the operating point (resonant frequency), and $\varepsilon_{2}$ the loss of a LSPR [26]. The strength or quality of a LSPR is a function of both parameters [26]:

$$
Q=\frac{\omega}{2 \varepsilon_{2}} \cdot \frac{d \varepsilon_{1}}{d \omega}
$$

The photon energy at which a LSPR peaks is also a function of the geometry of the nanoparticle, which can be parameterized as depolarization, $L(L=1 / 3$ corresponds to a sphere, lower values to prolate ellipsoids). The depolarization and material dielectric function are independent of one another, being respectively extrinsic and intrinsic to the properties of the condensed matter of the nanostructure. Here we make photon energy a 
dependent variable, tuning it to whatever energy is required to give the peak plasmon resonance for a particular combination of material and particle shape. In figure 7 we show the predicted effect of $L$ and $\varepsilon(\omega)$ on $C_{\mathrm{e}}$, the quasistatic extinction cross-section (normalized here by the volume $V$ of the particle) and on $Q$ (also for the quasistatic case). Clearly, pure $\mathrm{Au}$ remains the superior option, however, $\mathrm{AuCu}(\mathrm{I})$ and $(\mathrm{Au}, \mathrm{Cu})$ solid solution are both predicted to be superior to pure $\mathrm{Cu}$ in the range 2.2 to $2.5 \mathrm{eV}$ (500 to $570 \mathrm{~nm}$ ). Interestingly, the thin film $\mathrm{AuCu}$ retains this superiority over $\mathrm{Cu}$ to energies as low as $1.8 \mathrm{eV}(\sim 690 \mathrm{~nm})$.

\section{Conclusions}

The effect of ordering on the dielectric function of equiatomic $\mathrm{Au}-\mathrm{Cu}$ alloys has been examined using a combination of measurement and calculation. Contrary to some reports in the literature, the effect on the dielectric function is relatively minor and is masked by the characteristic scatter band of experimental measurements. Therefore, use of equiatomic $\mathrm{Au}-\mathrm{Cu}$ in nanostructures intended for plasmonic applications is not influenced by the presence or absence of ordering of the structure. As a material for use in plasmonic applications, $\mathrm{AuCu}$ is inferior to pure $\mathrm{Au}$, but in the important part of the spectrum lying between 1.8 and $2.5 \mathrm{eV}$ (corresponding to 690 and $500 \mathrm{~nm}$ respectively), this material is superior to pure $\mathrm{Cu}$.

\section{ACKNOWLEDGEMENTS}

The authors thank the Australian Research Council for support and Mr David McPherson for assisting with the preparation of the $\mathrm{AuCu}$ samples. The authors 
acknowledge use of facilities within the Monash Centre for Electron Microscopy, Melbourne, Australia

\section{REFERENCE}

1. Henkel, A., et al. 2009 Tuning plasmonic properties by alloying copper into gold nanorods. J. Phys. Chem. C. 113(6) 2200-2204.

2. Weaver, J.H. and H.P.R. Frederikse, Optical Properties of Selected Elements, in CRC Handbook of Chemistry and Physics, D.R. Lide, Editor. 2001, CRC Press: Boca Raton. p. 133.

3. Murray, J.L., Alloy Phase Diagrams. ASM Handbook. Vol. 3. 2002, Materials Park, Ohio: ASM Materials International.

4. Shiraishi, T., et al. 1997 Effects of small silver addition to $\mathrm{AuCu}$ on the $\mathrm{AuCu} \mathrm{I}$ ordering process and age-hardening behaviours J. Alloys Compounds. 257 306312.

5. Banhart, J. and G. Czycholl 2002 Electrical conductivity of long-range-ordered alloys. Europhys. Lett. 58(2) 264-270.

6. Hamana, D., L. Amiour, and L. Chetibi 2009 The apparition of a new reaction at lower temperature in equiatomic CuAu alloy. Phase Transitions. 82(10) 755766.

7. Köster, W. and R. Stahl 1967 Über den Einfluß von Legierungsbildung, Verformung und Rekristallisation sowie von Nahund Fernordnung auf optische Konstanten der Edelmetalle und ihrer Legierungen. Zeitschrift für Metallkunde. 58768.

8. Okamoto, H., et al. 1987 The Au-Cu (gold-copper) system. Bull. Alloy Phase Diagrams. 8(5) 454-473.

9. Rivory, J. 1974 Optical properties of ordered and disordered Au-Cu alloys $J$ de physique. 35 Colloque C4(5) 51-56.

10. Tanaka, Y., et al. 1998 Early stage of ordering in stoichiometric AuCu alloy. Mater. Trans. (JIM). 39(1) 87-94.

11. Nilsson, P.O., A. Persson, and S. Hagström 1968 Optical properties of $\mathrm{Cu}-\mathrm{Au}$ alloys. Solid State Comm. 6297 -299.

12. Shiraishi, T. and R.J.D. Tilley 2013 An estimation of the reflectivity of some monophasic binary gold alloys. Gold Bull. 47(1-2) 75-83.

13. Rivory, J. 1976 Optical properties of metastable Ag-Cu alloy films. Thin Solid Films. 37 345-350

14. Kim, M.-J., et al. 2003 Preparation and characterization of $\mathrm{Au}-\mathrm{Ag}$ and $\mathrm{Au}-\mathrm{Cu}$ alloy nanoparticles in chloroform. J. Mater. Chem. 13 1789-1792.

15. Cattaruzza, E., et al. $2007 \mathrm{Au}-\mathrm{Cu}$ nanoparticles in silica glass as composite material for photonic applications. Appl. Surf. Sci. 254 1017-1021.

16. Sanchez-Ramirez, J.F., L. Vazquez, and U. Pal 2002 Preparation and optical absorption of colloidal dispersion of $\mathrm{Au} / \mathrm{Cu}$ nanoparticles. Superficies y vacio. 15 16-18.

17. Cortie, M.B. and A.M. McDonagh 2011 Optical properties of hybrid and alloy plasmonic nanoparticles. Chem. Rev. 111(6) 3713-3735. 
18. Keast, V.J., R.L. Barnett, and M.B. Cortie 2014 First principles calculations of the optical and plasmonic response of Au alloys and intermetallic compounds. $J$. Phys. Cond. Matter. 26(S) article 305501.

19. Scott, W.R. and L. Muldawer 1976 Optical properties of ordered and disordered CuAu. Phys. Rev. B. 14(10) 4426-4430.

20. Nilsson, P.O. and C. Norris 1969 Order-disorder effects in $\mathrm{AuCu}_{3}$ observed in reflectivity and photoemission Phys. Lett. 29AA(1) 22-23.

21. Scott, W. and L. Muldawer 1974 Optical properties and electronic structure of ordered and disordered $\mathrm{Cu}_{3} \mathrm{Au}$. Phys. Rev. B. 9(4) 1115-1125.

22. Schwarz, K., P. Blaha, and G.K.H. Madsen 2002 Electronic structure calculations of solids using the WIEN2k package for material sciences. Computer Physics Communications. 147 71-76.

23. Perdew, J.P., S. Burke, and M. Ernzerhof 1996 Phys. Rev. Lett. 773865.

24. Ambrosch-Draxl, C. and J.O. Sofo 2006 Linear optical properties of solids within the full-potential linearized augmented planewave method. Computer Physics Communications. 175(1) 1-14.

25. $\mathrm{Xu}, \mathrm{Z}$., et al. 2012 Compositional dependence of the stability of $\mathrm{AuCu}$ alloy nanoparticles. Chem. Comm. 48 5626-5628.

26. Arnold, M.D. and M.G. Blaber 2009 Optical performance and metallic absorption in nanoplasmonic systems. Optics Express. 17(5) 3835-3847.

27. Cortie, M.B. and F.C. Levey 2000 Structure and ordering of the 18-carat Al-Au$\mathrm{Cu} \beta$ phase. Intermetallics. 8(7) 793-804.

28. Van Tendeloo, G., et al. 1986 The initial stages of ordering in $\mathrm{CuAu}-\mathrm{I}$ and $\mathrm{CuAu}$ II J. Mater. Sci. 21(12) 4395-4402.

29. Alkauskas, A., S.D. Schneider, and C. Hébert 2013 Dynamic structure factors of $\mathrm{Cu}, \mathrm{Ag}$, and $\mathrm{Au}$ : Comparative study from first principles. Phys. Rev. B. 88 195124.

30. Marini, A. and R.D. Sole 2003 Bound excitons in time-dependent densityfunctional theory: Optical and energy-loss spectra. Phys. Rev. Lett. 91(12) 176402.

31. Marini, A., R.D. Sole, and G. Onida 2002 First-principles calculation of the plasmon resonance and of the reflectance spectrum of silver in the GW approximation. Phys. Rev. B. 66115101.

32. Marini, A., G. Onida, and R.D. Sole 2002 Quasiparticle electronic structure of copper in the GW approximation. Phys. Rev. Lett. 88016403.

33. Aspnes, D.E., E. Kinsbron, and D.D. Bacon 1980 Optical properties of Au: Sample effects. Phys. Rev. B. 21(8) 3290-3299. 


\section{Figure captions}

Fig.1. (Color online) Atomic configuration of two $\mathrm{Au}-\mathrm{Cu}$ unit cells based on equiatomic fcc $(\mathrm{Au}, \mathrm{Cu}),(\mathrm{a})$ unit cell D2, (b) unit cell D3.

Fig. 2. Microstructure of $\mathrm{Au}-\mathrm{Cu}$ samples. (a) Transmission electron micrograph and electron diffraction pattern of furnace-cooled sample. (b) Transmission electron micrograph and electron diffraction pattern of quenched-cooled sample. (c) Atomic resolution transmission electron micrograph of quenched sample along [011] direction showing absence of laths or twins.

Fig.3 (Color online) Portion of the X-ray diffraction pattern of a series of thin film samples. (i) Poorly crystalline fcc sample after deposition at room temperature. (ii) Heat treating at $450{ }^{\circ} \mathrm{C}$ causes grains to grow and intensity of the $\{220\}$ fcc peak to grow. (iii) A further heat treatment for 20 minutes at $375^{\circ} \mathrm{C}$ causes the sample to transform to $\mathrm{AuCu}(\mathrm{I})$, as indicated by the appearance of reflections characteristic of the $(220)_{\mathrm{AuCu}(\mathrm{I})}$ and $(022)_{\mathrm{AuCu}(\mathrm{I})}$.

Fig. 4. (Color online) $\varepsilon_{2}$ values of $\mathrm{Au}, \mathrm{Cu}, \mathrm{AuCu}$ and ( $\mathrm{Au}, \mathrm{Cu}$ ). (a) Calculated and measured values for $\mathrm{Au}$. (b) Calculated and measured values for $\mathrm{Cu}$. Literature values for elemental $\mathrm{Au}$ and $\mathrm{Cu}$ are from Henkel et al. [1] and the CRC Handbook of Chemistry and Physics [2]. (c) $\varepsilon_{2}$ for the ordered (O) and disordered (D1-D3) AuCu unit cells calculated here using DFT. (d) Experimental values of $\varepsilon_{2}$. Values of $\varepsilon_{2}$ for $\mathrm{AuCu}$ 
from the literature are shown from Köster and Stahl ('K\&S') [7], Rivory [9] and Scott and Muldawer ('S\&M')

Fig. 5. (Color online) Measured, calculated and literature values for $\varepsilon_{1}$ for $(\mathrm{Au}, \mathrm{Cu})$ and $\mathrm{AuCu}(\mathrm{I})$. Literature values for elemental $\mathrm{Au}$ and $\mathrm{Cu}$ are from Henkel et al. [1] and the CRC Handbook of Chemistry and Physics [2]

Fig. 6. (Color online) Density of states for (a) ordered alloy and (b) the disordered alloy (corresponding to the $4 \mathrm{x} 1$ supercell D3).

Fig. 7. (Color online) Comparison of the predicted capability of $\mathrm{Au}, \mathrm{Cu}$ and various equiatomic $\mathrm{Au}-\mathrm{Cu}$ materials to generate localized surface plasmon resonances in suitable nanostructures. 